\title{
BMJ Open Endoscopic submucosal dissection versus endoscopic mucosal resection for patients with early gastric cancer: a meta-analysis
}

Maogen Tao, Xiaobo Zhou, Meiqing Hu, Jun Pan

To cite: Tao M, Zhou X, Hu M, et al. Endoscopic submucosal dissection versus endoscopic mucosal resection for patients with early gastric cancer: a meta-analysis. BMJ Open 2019;9:e025803. doi:10.1136 bmjopen-2018-025803

- Prepublication history and additional material for this paper are available online. To view these files, please visit the journal online (http://dx.doi. org/10.1136/bmjopen-2018025803).

Received 18 September 2018 Revised 28 June 2019 Accepted 03 September 2019

Check for updates

(C) Author(s) (or their employer(s)) 2019. Re-use permitted under CC BY-NC. No commercial re-use. See rights and permissions. Published by BMJ.

Department of Gastroenterology, Lanxi People's Hospital, Lanxi, China

Correspondence to

Dr Maogen Tao;

taomaogen1058@163.com

\section{ABSTRACT}

Objectives To investigate the treatment effects of endoscopic submucosal dissection (ESD) versus endoscopic mucosal resection (EMR) for early gastric cancer (EGC).

Design Meta-analysis.

Methods We systematically searched three electronic databases, including PubMed, EmBase and the Cochrane library for studies published with inception to January 2018. The eligible studies should be evaluated for the efficacy and safety of ESD versus EMR for patients with EGC. The summary ORs and standard mean differences (SMDs) with 95\% Cls were employed as effect estimates. Sensitivity analyses were conducted to evaluate the impact of single study on overall analysis. Subgroup analyses were performed for investigated outcomes to evaluate the treatment effects of ESD versus EMR for patients with EGC with specific subsets.

Results Eighteen studies, with a total of 6723 patients with EGC, were included in final analysis. The summary ORs indicated that patients with EGC who received ESD were associated with an increased incidence of en bloc resection (OR: 9.00; 95\% Cl: 6.66 to 12.17; $p<0.001$ ), complete resection (OR: 8.43 ; $95 \% \mathrm{Cl}: 5.04$ to 14.09 ; $\mathrm{p}<0.001)$ and curative resection (OR: $2.92 ; 95 \% \mathrm{Cl}: 1.85$ to 4.61; $p<0.001$ ) when compared with EMR. Furthermore, ESD was associated with lower risk of local recurrence (OR: $0.18 ; 95 \% \mathrm{Cl}: 0.09$ to $0.34 ; \mathrm{p}<0.001$ ). In addition, there was no significant difference between ESD and EMR for the risk of bleeding (OR: 1.26; $95 \% \mathrm{Cl}: 0.88$ to 1.80; $\mathrm{p}=0.203)$. Though, ESD was correlated with greater risk of perforation (OR: 2.55 ; $95 \% \mathrm{Cl}: 1.48$ to 4.39 ; $\mathrm{p}=0.001$ ), and longer operation time (SMD: $1.12 ; 95 \% \mathrm{Cl}: 0.13$ to 2.10; $p=0.026$ ) as compared with EMR. Additionally, several different features observed in included studies and patients could bias the effectiveness of ESD versus EMR in patients with EGC.

Conclusions ESD is superior than EMR for en bloc resection, complete resection, curative resection and local recurrence, while it increased perforation risk and longer operation time.

\section{INTRODUCTION}

Gastric cancer (GC) is the second most common cancer worldwide, which accounts for approximately 0.93 million new cases per
Strengths and limitations of this study

- We did a meta-analysis to investigate the treatment effects of endoscopic submucosal dissection (ESD) versus endoscopic mucosal resection (EMR) for early gastric cancer (EGC)

- Several different features observed in included studies and patients could bias the effectiveness of ESD versus EMR in patients with EGC.

- This quantitative analysis was based on published studies and thus publication bias was inevitable.

- The summary analysis was based on pooled data and individual data were not available, which restricted us from conducting more detailing analysis.

year, among which two-thirds come from Asian countries, such as China, Japan and Korea. ${ }^{1-3}$ Early diagnostic of GC is extremely important for the endoscopic treatment; early gastric cancer (EGC) is defined as malignant lesion that does not go beyond the submucosal layer of the stomach wall irrespective of the presence of lymph node metastasis. ${ }^{4}$ Nevertheless, in China the detection rate of patients with EGC is still low (10\%) compared with some other countries. ${ }^{56}$ Therapeutic endoscopic resection has been used for EGC since the mid-1980s and is still regarded as standard treatment strategy for patients with EGC without lymph node metastasis. ${ }^{78}$ Yet, the effectiveness of endoscopic submucosal dissection (ESD) and endoscopic mucosal resection (EMR) for patients with EGC still remains controversial.

The techniques for ESD were developed since the 1990s, which was associated with expanded indication range for endoscopic resection. $^{9}$ Moreover, EMR was initially carried out through strip biopsy, which are developed combined with a cap-fitted panendoscope and aspiration mucosectomy. ${ }^{8}$ Previous studies have demonstrated that EMR is useful for endoscopically resectable lesions, 


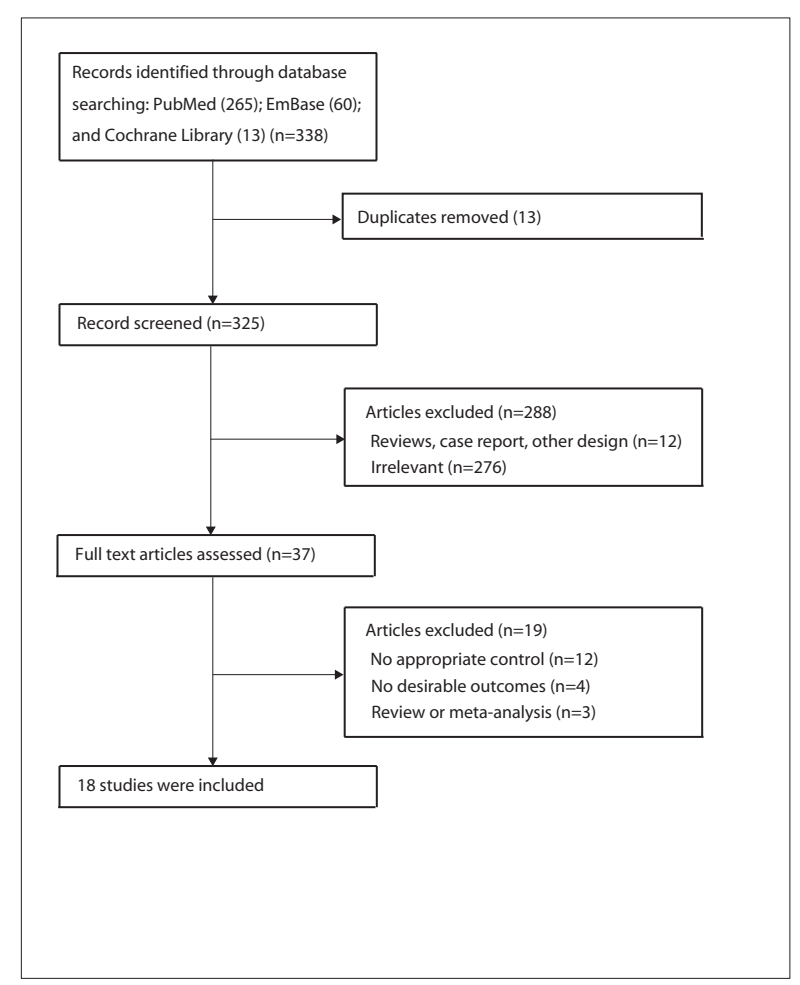

Figure 1 Flow diagram of the literature search and selection process of trials.

but not for histological assessment and cases with high risk of local recurrence. ${ }^{10-12}$ Contrary, ESD has shown to be beneficial for one-piece resection in patients with large and ulcerative lesions regardless of tumour location. ${ }^{13-15}$ Compared with EMR, many studies have shown that patients with EGC who received ESD could achieve higher en bloc resection rate and accurate histological assessment, which in turn could reduce the risk of local recurrence. ${ }^{16} 17$ However, numerous other outcome variables did not provide data suitable for direct comparisons, thus the effectiveness of ESD versus EMR for needs of patients with EGC to be further clarified. The following study thoroughly investigates the efficacy and safety of ESD versus EMR in treating patients with EGC by conducting a comprehensive quantitative meta-analysis.

\section{MATERIALS AND METHODS}

\section{Data sources, search strategy and selection criteria}

This meta-analysis was performed according to the Meta-Analysis of Observational Studies in Epidemiology guidelines. ${ }^{18}$ We performed a systematical search of PubMed (http:// www.ncbi.nlm.nih.gov/pubmed/), Embase (http://www.embase.com/) and Cochrane Library (http://www.thecochranelibrary.com/) databases looking for the studies published through January 2018 which evaluated the effectiveness of ESD versus EMR for patients with EGC. We used the following texts and keywords in combination with both MeSH terms and text words: ("stomach" or "gastric") AND ("neoplasms" or "carcinoma" or "cancer" or "adenocarcinoma") AND "endoscopic submucosal dissection" AND "endoscopic mucosal resection". The details of search strategy are shows in online supplementary file 1. Manual searches of reference lists from potential studies were conducted to select additional eligible studies.

The eligible studies were identified through an initial screen of abstracts and titles, while the second screening included the examination of the full-text of the articles. Two authors evaluated the study selection process independently, and any inconsistencies were resolved by an additional author until a consensus was reached. The studies were eligible for inclusion if they met the following: (1) studies with prospective or retrospective design; (2) patients with EGC; (3) studies which investigated the effectiveness of ESD versus EMR and (4) those reporting at least one of the following outcomes: en bloc resection, complete resection, curative resection, local recurrence, bleeding, perforation and operation time.

\section{Data collection and quality assessment}

Two authors independently abstracted and evaluated the following items in each study according to the standard protocols: first author's surname, publication year, country, study design, number of lesions, mean age, percentage of male, mean size of lesions, disease status and follow-up duration, while any inconsistencies were determined by group discussion and referring to the original article. The methodological quality of included studies was assessed using the Newcastle-Ottawa Scale (NOS), which is comprehensive method for evaluating the quality of observational studies in meta-analysis. ${ }^{19}$ The NOS consisted of three subscales including the representative of participants, comparability and outcomes, which ranged from 0 to 9 -star system. Studies that were awarded score equal or higher than 6 were regarded of high quality.

\section{Statistical analysis}

The summary ORs with corresponding 95\% CIs were employed to calculate the dichotomy outcomes including en bloc resection, complete resection, curative resection, local recurrence, bleeding and perforation, while the standard mean difference (SMD) with $95 \%$ CI was used to evaluate the difference between ESD and EMR for operation time. The summary results were calculated using the Dersimonian and Laird random-effects models. ${ }^{20}{ }_{21}$ Heterogeneity among studies was investigated by $\mathrm{I}^{2}$, if $\mathrm{I}^{2}$ $>50 \%$ was regarded as significant heterogeneity. ${ }^{22}{ }^{23}$ Sensitivity analyses for investigated outcomes were conducted to evaluate the impact of single study on overall analysis. ${ }^{24}$ Furthermore, subgroup analyses were performed according to publication year, study design, number of lesions, mean age, percentage of male, disease status and follow-up duration. The interaction $\mathrm{p}$ value, which was based on Student's t-test distribution due to small number of included studies, was also calculated to compare the difference between subgroups. ${ }^{25}$ Publication biases were calculated for investigated outcomes by using Egger 
Table 1 Baseline characteristics of included patients and studies in the meta-analysis

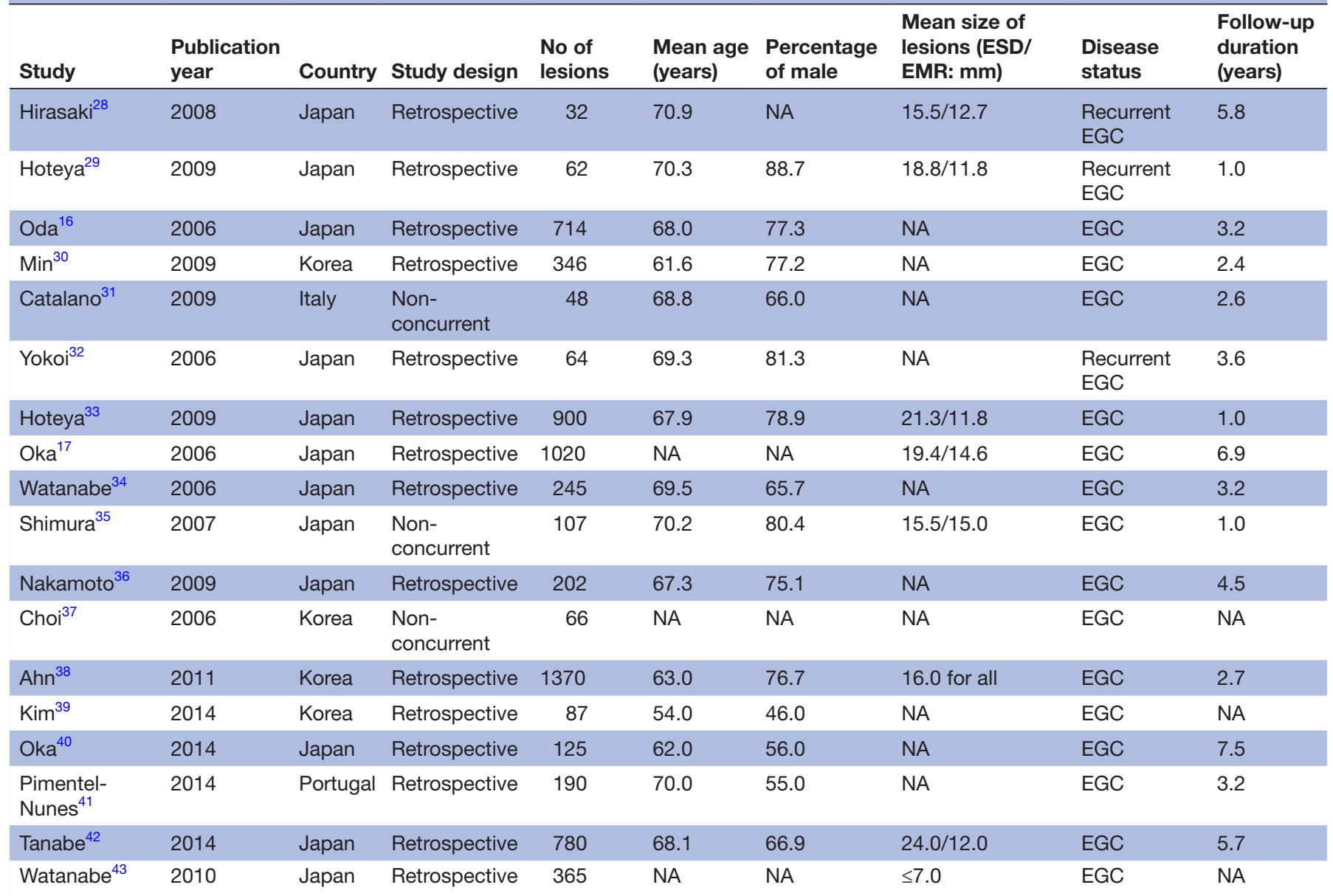

EGC, early gastric cancer; EMR, endoscopic mucosal resection; ESD, endoscopic submucosal dissection; NA, not available.

and Begg tests. ${ }^{26} 27$ All reported p values were two sided, and $p$ value $<0.05$ was considered statistically significant. Statistical analyses were performed using STATA software (V.10.0; Stata Corporation, College Station, Texas, USA).

Patient and public involvement

Not applicable.

\section{RESULTS}

\section{Literature search}

Figure 1 shows a flow diagram of relevant studies' selection process. The initial electronic search produced 338 articles; 301 studies were excluded based on initial screening of titles and abstracts. Full texts for the remaining 37 studies were retrieved to select relevant studies. Finally, 18 studies including 6723 patients with EGC were finally recruited into this meta-analysis. ${ }^{16} 17$ 28-43 Manual search of the reference lists from included studies did not yield new eligible studies.

\section{Study characteristics}

We selected a total of 15 retrospective and 3 non-concurrent studies, which included 6723 patients with EGC. Table 1 summarised the general characteristics of the included studies. The included studies were performed in the Japan $(\mathrm{n}=12)$, Korea $(\mathrm{n}=4)$, Italy $(\mathrm{n}=1)$ and Portugal $(\mathrm{n}=1)$. The follow-up period for participants was 1.0-7.5 years, while 32-1370 lesions were included in each study. Fifteen studies included patients with EGC, and the remaining three studies included patients with recurrent EGC. Study quality was assessed by NOS and is shown in online supplementary file 2. Overall, three studies scored 7, nine studies scored 6 and the remaining six studies scored 5 .

\section{En bloc resection}

Data for the effectiveness of ESD versus EMR for en bloc resection were available in 13 studies (14 cohorts). Briefly, en bloc resection rate resulted significantly higher in ESD patients (OR: 9.00; 95\% CI: 6.66 to 12.17 ; $\mathrm{p}<0.001$; with moderate heterogeneity; figure 2). The result of sensitivity analysis was not altered after sequential exclusion of a single study (online supplementary file 3 ). Subgroup analyses found these significant differences were persisted in each subgroup, and percentage of male might affect the effectiveness of ESD versus EMR for patients with EGC (table 2). Finally, there was no significant publication bias by Egger and Begg test results ( $p$ value for Egger: 0.367; $p$ value for Begg: 0.274; table 3). 


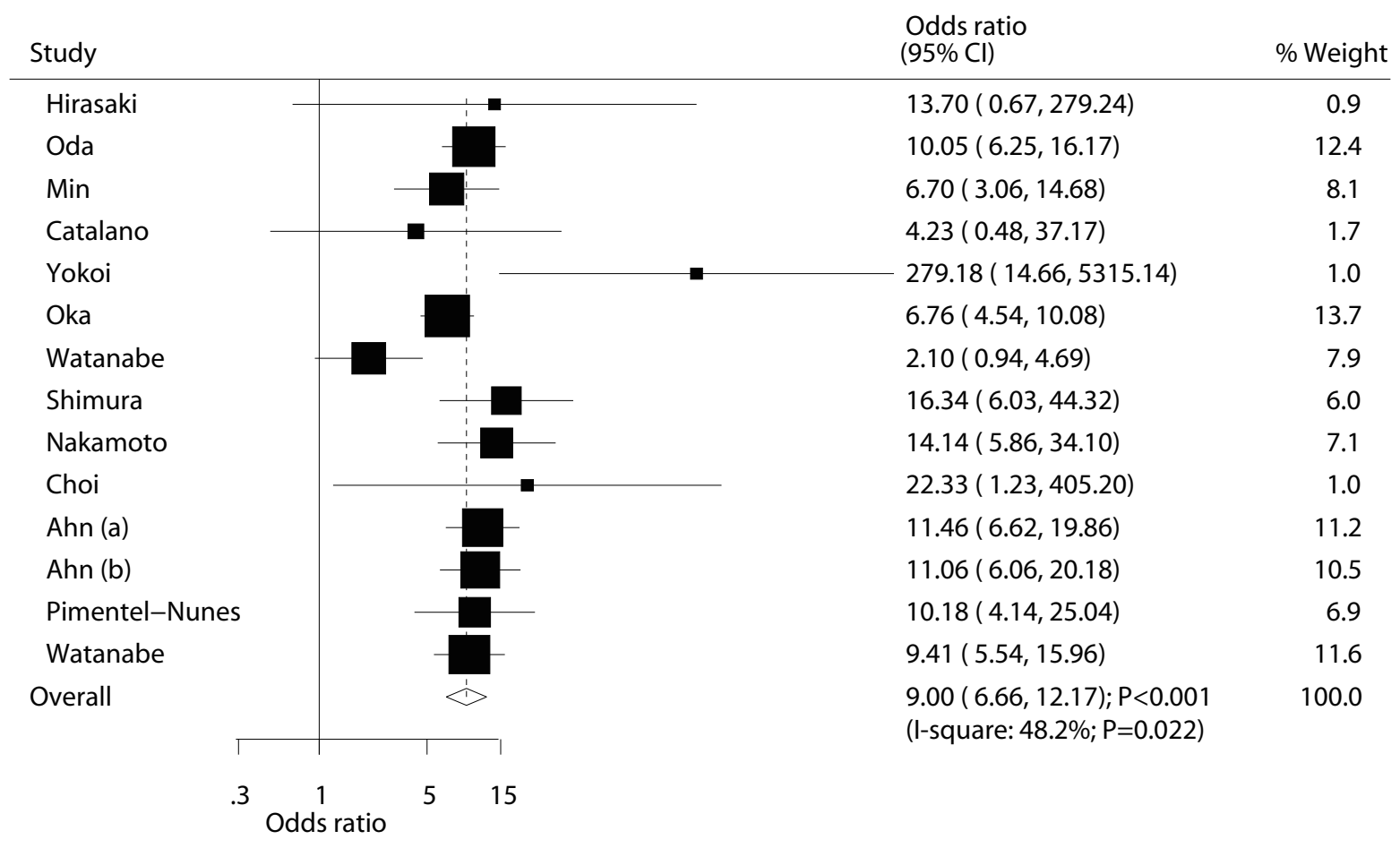

Figure 2 Effect of endoscopic submucosaldissection on the incidence of en bloc resection in patients with early gastric cancer.

\section{Complete resection}

Data for the effectiveness of ESD versus EMR for complete resection were available in 11 studies (12 cohorts). Overall, complete resection rate was significantly higher in ESD patients (OR: 8.43; 95\% CI: 5.04 to 14.09; $<<0.001$; with substantial heterogeneity; figure 3 ). After sequential exclusion, we noted that summary result was not changed (online supplementary file 3). The findings from subgroup analyses were consistent with overall analysis, while publication year, mean age, percentage of male and follow-up duration have been associated with the treatment effects of ESD versus EMR for patients with EGC (table 2). Furthermore, no publication bias was observed for complete resection ( $p$ value for Egger: 0.668; $p$ value for Begg: 0.373; table 3).

\section{Curative resection}

Data for the effectiveness of ESD versus EMR for curative resection were available in six studies. Overall, curative resection rate was significantly higher in ESD patients (OR: 2.92; 95\% CI: 1.85 to 4.61; p<0.001; with substantial heterogeneity; figure 4). Sensitivity analysis was conducted, and the conclusion was not changed (online supplementary file 3). Although the results in most subgroups were statistically significant, we found no significant difference between ESD and EMR for curative resection if: the study was published in 2010 or after, the mean age of patients was $\geq 70$ years and the percentage of male was $<70 \%$. Interaction $p$ value suggested that sample size, disease status and follow-up duration could affect the effectiveness of ESD versus EMR for curative resection (table 2). In addition, there was no significant publication bias for curative resection ( $\mathrm{p}$ value for Egger: 0.352; $\mathrm{p}$ value for Begg: 1.000).

\section{Local recurrence}

Data for the effectiveness of ESD versus EMR for local recurrence were available in 12 studies (13 cohorts). The summary OR suggested that ESD was associated with a reduced risk of local recurrence (OR: 0.18; 95\% CI: 0.09 to $0.34 ; \mathrm{p}<0.001$; with moderate heterogeneity; figure 5 ). The conclusions of sensitivity analyses were not altered by sequential excluding single studies (online supplementary file 3). Furthermore, the results of subgroup analyses were consistent with overall analysis (table 2). Finally, no significant publication bias for local recurrence was observed ( $\mathrm{p}$ value for Egger: 0.099; $\mathrm{p}$ value for Begg: 0.360 ; table 3$)$.

\section{Post-treatment bleeding}

Risks of bleeding after ESD and EMR were available in 15 studies (16 cohorts). The summary OR indicated no significant difference between ESD and EMR for the risk of bleeding (OR: 1.26 ; $95 \%$ CI: 0.88 to $1.80 ; \mathrm{p}=0.203$; with moderate heterogeneity; figure 6). After sequential exclusion of individual study, the summary results were not altered (online supplementary file 3 ). Subgroup analyses indicated no significant differences between ESD and EMR for bleeding risk in all of subsets, while mean age, percentage of male and follow-up duration might affect the effectiveness of ESD versus EMR for patients with EGC (table 2). The Egger and Begg test results suggested no publication bias for bleeding ( $p$ value for Egger: 0.096; p value for Begg: 0.392; table 3). 
Table 2 Subgroup analyses for investigated outcomes

\begin{tabular}{|c|c|c|c|c|c|c|}
\hline Factors & Group & $\begin{array}{l}\text { No of included } \\
\text { cohorts }\end{array}$ & $\begin{array}{l}\text { OR or SMR and } \\
95 \% \mathrm{Cl}\end{array}$ & $P$ value & Heterogeneity (\%) & $\begin{array}{l}\text { P value between } \\
\text { subgroups }\end{array}$ \\
\hline \multirow{16}{*}{$\begin{array}{l}\text { En bloc resection } \\
\text { rates }\end{array}$} & \multicolumn{6}{|l|}{ Publication year } \\
\hline & Before 2010 & 10 & $8.43(5.20$ to 13.67$)$ & $<0.001$ & 60.1 & 0.135 \\
\hline & \multicolumn{6}{|l|}{ Study design } \\
\hline & Non-concurrent & 2 & 13.56 (5.71 to 32.22$)$ & $<0.001$ & 0.0 & 0.311 \\
\hline & \multicolumn{6}{|l|}{ Sample size } \\
\hline & $\geq 100$ & 10 & 8.69 (6.48 to 11.65$)$ & $<0.001$ & 52.1 & 0.287 \\
\hline & $<100$ & 4 & 21.01 (3.52 to 125.45$)$ & 0.001 & 41.8 & \\
\hline & \multicolumn{6}{|l|}{ Mean age (years) } \\
\hline & $\geq 70$ & 3 & 12.64 (6.58 to 24.27 ) & $<0.001$ & 0.0 & 0.405 \\
\hline & $<70$ & 3 & $4.48(1.36$ to 14.69$)$ & 0.013 & 69.7 & \\
\hline & \multicolumn{6}{|l|}{ Disease status } \\
\hline & EGC & 12 & $8.66(6.55$ to 11.45$)$ & $<0.001$ & 44.0 & 0.062 \\
\hline & Recurrent EGC & 2 & $\begin{array}{l}62.93(3.28 \text { to } \\
1208.40)\end{array}$ & 0.006 & 49.1 & \\
\hline & \multicolumn{6}{|c|}{ Follow-up duration (years) } \\
\hline & $\geq 3.0$ & 7 & 8.38 (4.72 to 14.90$)$ & $<0.001$ & 69.7 & 0.343 \\
\hline & $<3.0$ & 5 & $10.45(7.47$ to 14.60$)$ & $<0.001$ & 0.0 & \\
\hline \multirow{15}{*}{$\begin{array}{l}\text { Complete resection } \\
\text { rates }\end{array}$} & \multicolumn{6}{|l|}{ Publication year } \\
\hline & Before 2010 & 7 & 14.11 (10.85 to 18.35$)$ & $<0.001$ & 0.0 & $<0.001$ \\
\hline & \multicolumn{6}{|l|}{ Study design } \\
\hline & \multicolumn{6}{|l|}{ Mean age (years) } \\
\hline & $\geq 70$ & 3 & 15.13 (7.11 to 32.23$)$ & $<0.001$ & 0.0 & 0.003 \\
\hline & $<70$ & 7 & 6.44 (3.24 to 12.80$)$ & $<0.001$ & 86.2 & \\
\hline & \multicolumn{6}{|c|}{ Percentage of male } \\
\hline & $\geq 70$ & 6 & 8.29 (3.48 to 19.78$)$ & $<0.001$ & 88.1 & 0.003 \\
\hline & $<70$ & 3 & 9.43 (5.33 to 16.69$)$ & $<0.001$ & 23.8 & \\
\hline & \multicolumn{6}{|l|}{ Disease status } \\
\hline & EGC & 10 & 7.92 (4.55 to 13.79$)$ & $<0.001$ & 83.8 & 0.490 \\
\hline & Recurrent EGC & 2 & 13.70 (3.59 to 52.29$)$ & $<0.001$ & 25.2 & \\
\hline & \multicolumn{6}{|c|}{ Follow-up duration (years) } \\
\hline & $\geq 3.0$ & 5 & 13.37 (9.94 to 18.00$)$ & $<0.001$ & 12.6 & $<0.001$ \\
\hline & $<3.0$ & 5 & 6.84 (2.66 to 17.54$)$ & $<0.001$ & 88.0 & \\
\hline
\end{tabular}


Table 2 Continued

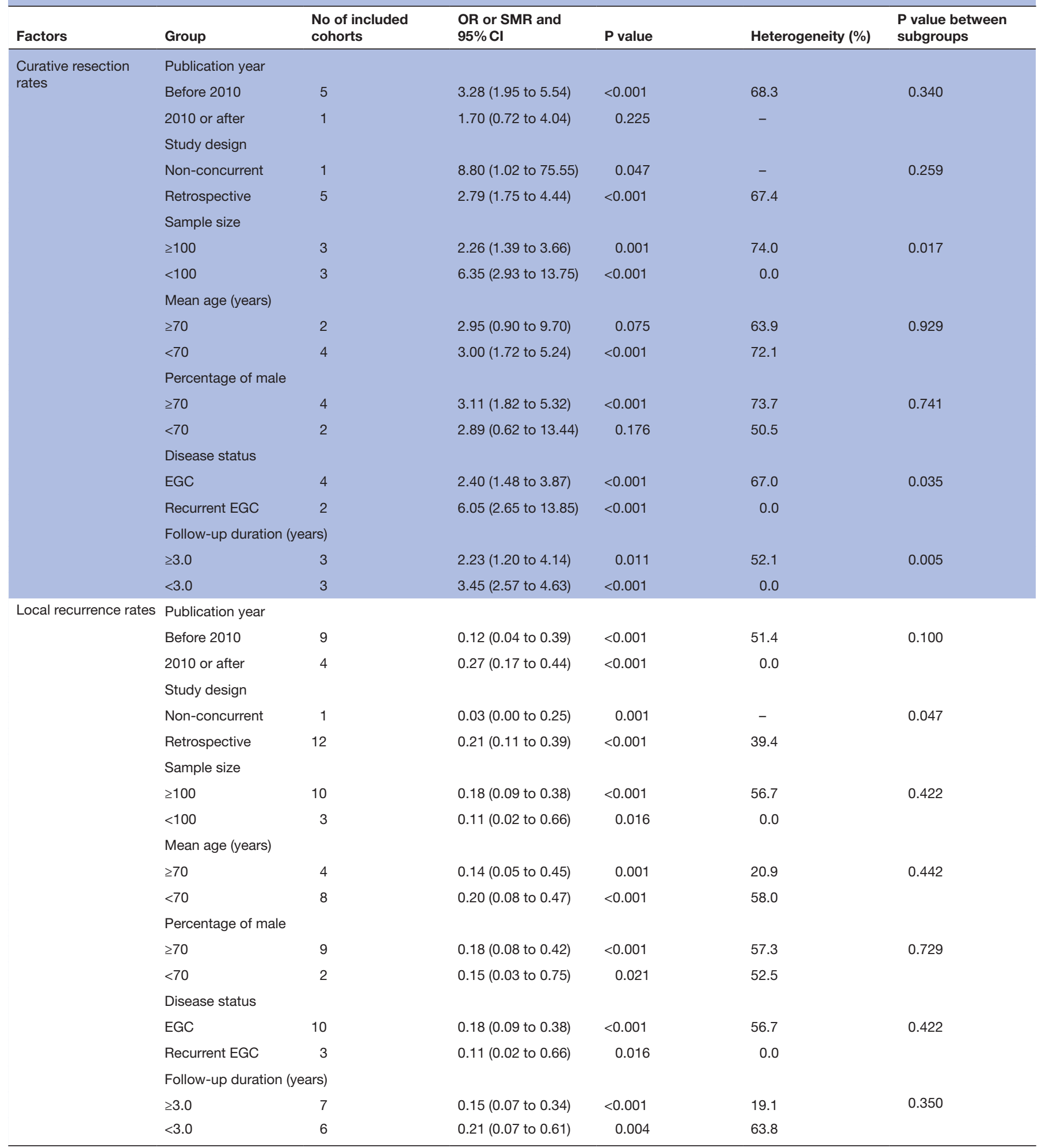

Continued 
Table 2 Continued

\begin{tabular}{|c|c|c|c|c|c|c|}
\hline Factors & Group & $\begin{array}{l}\text { No of included } \\
\text { cohorts }\end{array}$ & $\begin{array}{l}\text { OR or SMR and } \\
95 \% \mathrm{Cl}\end{array}$ & $P$ value & Heterogeneity (\%) & $\begin{array}{l}\text { P value between } \\
\text { subgroups }\end{array}$ \\
\hline \multirow[t]{17}{*}{ Bleeding } & \multicolumn{6}{|l|}{ Publication year } \\
\hline & Before 2010 & 10 & $1.26(0.72$ to 2.21$)$ & 0.413 & 51.0 & 0.032 \\
\hline & 2010 or after & 6 & $1.16(0.82$ to 1.64$)$ & 0.416 & 5.7 & \\
\hline & \multicolumn{6}{|l|}{ Study design } \\
\hline & Non-concurrent & 3 & 0.88 (0.38 to 2.06$)$ & 0.767 & 0.0 & 0.191 \\
\hline & \multicolumn{6}{|l|}{ Sample size } \\
\hline & $\geq 100$ & 11 & 1.31 (0.86 to 1.99$)$ & 0.215 & 59.6 & 0.335 \\
\hline & $<100$ & 5 & 1.07 (0.51 to 2.26$)$ & 0.853 & 0.0 & \\
\hline & \multicolumn{6}{|l|}{ Mean age (years) } \\
\hline & $\geq 70$ & 4 & 0.78 (0.40 to 1.54$)$ & 0.481 & 0.0 & $<0.001$ \\
\hline & $<70$ & 5 & 1.44 (0.87 to 2.38$)$ & 0.155 & 0.0 & \\
\hline & \multicolumn{6}{|l|}{ Disease status } \\
\hline & EGC & 14 & 1.30 (0.89 to 1.89$)$ & 0.175 & 51.8 & 0.288 \\
\hline & Recurrent EGC & 2 & $0.72(0.18$ to 2.91$)$ & 0.646 & 0.0 & \\
\hline & \multicolumn{6}{|c|}{ Follow-up duration (years) } \\
\hline & $\geq 3.0$ & 7 & 1.54 (0.81 to 2.92$)$ & 0.190 & 51.7 & 0.001 \\
\hline & $<3.0$ & 7 & $1.00(0.73$ to 1.38$)$ & 0.999 & 0.0 & \\
\hline \multirow[t]{15}{*}{ Perforation rates } & \multicolumn{6}{|l|}{ Publication year } \\
\hline & Before 2010 & 11 & 3.73 (1.99 to 6.99$)$ & $<0.001$ & 30.9 & 0.003 \\
\hline & 2010 or after & 6 & 1.19 (0.65 to 2.19$)$ & 0.578 & 0.0 & \\
\hline & \multicolumn{6}{|l|}{ Mean age (years) } \\
\hline & $\geq 70$ & 3 & $1.53(0.30$ to 7.88$)$ & 0.611 & 0.0 & $<0.001$ \\
\hline & $<70$ & 12 & $1.82(1.20$ to 2.77$)$ & 0.005 & 0.0 & \\
\hline & \multicolumn{6}{|c|}{ Percentage of male } \\
\hline & $\geq 70$ & 9 & 2.54 (1.49 to 4.32$)$ & 0.001 & 0.0 & $<0.001$ \\
\hline & $<70$ & 6 & $1.12(0.60$ to 2.10$)$ & 0.719 & 0.0 & \\
\hline & \multicolumn{6}{|l|}{ Disease status } \\
\hline & EGC & 15 & 2.54 (1.42 to 4.57$)$ & 0.002 & 47.0 & 0.935 \\
\hline & Recurrent EGC & 2 & 2.68 (0.30 to 23.99$)$ & 0.377 & 0.0 & \\
\hline & \multicolumn{6}{|c|}{ Follow-up duration (years) } \\
\hline & $\geq 3.0$ & 8 & 2.31 (0.82 to 6.56$)$ & 0.114 & 71.8 & 0.955 \\
\hline & $<3.0$ & 7 & 2.38 (1.27 to 4.47$)$ & 0.007 & 0.0 & \\
\hline
\end{tabular}

Continued 


\begin{tabular}{|c|c|c|c|c|c|c|}
\hline Factors & Group & $\begin{array}{l}\text { No of included } \\
\text { cohorts }\end{array}$ & $\begin{array}{l}\text { OR or SMR and } \\
95 \% \mathrm{Cl}\end{array}$ & $P$ value & Heterogeneity (\%) & $\begin{array}{l}P \text { value between } \\
\text { subgroups }\end{array}$ \\
\hline & Before 2010 & 7 & 1.57 (0.75 to 2.38$)$ & $<0.001$ & 97.4 & \multirow[t]{2}{*}{$<0.001$} \\
\hline & 2010 or after & 1 & $-2.03(-2.55$ to -1.51$)$ & $<0.001$ & - & \\
\hline & \multicolumn{6}{|l|}{ Study design } \\
\hline & Retrospective & 7 & $1.09(-0.00$ to 2.19$)$ & 0.051 & 98.6 & 0.464 \\
\hline & \multicolumn{6}{|l|}{ Sample size } \\
\hline & $\geq 100$ & 4 & $1.48(0.31$ to 2.65$)$ & 0.013 & 98.7 & \multirow[t]{2}{*}{$<0.001$} \\
\hline & $<100$ & 4 & $0.75(-1.28$ to 2.78$)$ & 0.470 & 97.7 & \\
\hline & \multicolumn{6}{|l|}{ Mean age (years) } \\
\hline & $\geq 70$ & 3 & 1.34 (0.51 to 2.17$)$ & 0.002 & 93.9 & \multirow[t]{2}{*}{$<0.001$} \\
\hline & $<70$ & 2 & $-0.41(-3.58$ to 2.76$)$ & 0.800 & 98.9 & \\
\hline & \multicolumn{6}{|l|}{ Disease status } \\
\hline & EGC & 6 & $0.88(-0.30$ to 2.06$)$ & 0.144 & 98.8 & \multirow[t]{2}{*}{0.090} \\
\hline & Recurrent EGC & 2 & 1.90 (1.13 to 2.67$)$ & $<0.001$ & 56.0 & \\
\hline & \multicolumn{6}{|c|}{ Follow-up duration (years) } \\
\hline & $\geq 3.0$ & 4 & 1.73 (0.76 to 2.69$)$ & $<0.001$ & 96.6 & \multirow[t]{2}{*}{$<0.001$} \\
\hline & $<3.0$ & 2 & $1.38(-0.30$ to 3.06$)$ & 0.107 & 95.7 & \\
\hline
\end{tabular}

EGC, early gastric cancer; SMR, standard mean difference.

\section{Perforation}

Data for the effectiveness of ESD versus EMR for perforation were available in 16 studies ( 17 cohorts). The summary OR suggested ESD was associated with an increased risk of perforation compared with EMR (OR: 2.55; $95 \%$ CI: 1.48 to $4.39 ; \mathrm{p}=0.001$; with moderate heterogeneity; figure 7). Sensitivity analyses revealed that results were statistically significant (online supplementary file 3). Additionally, the subgroup analyses suggested that the significant difference in the treatment effect between ESD and EMR for perforation was mainly due to the studies published before 2010, study with retrospective design, sample size $\geq 100$, mean age $<70.0$ years, percentage of male $\geq 70 \%$, patients with

\begin{tabular}{|c|c|c|}
\hline Outcomes & $P$ value for Egger & $P$ value for Begg \\
\hline En bloc resection rates & 0.367 & 0.274 \\
\hline $\begin{array}{l}\text { Complete resection } \\
\text { rates }\end{array}$ & 0.668 & 0.373 \\
\hline $\begin{array}{l}\text { Curative resection } \\
\text { rates }\end{array}$ & 0.352 & 1.000 \\
\hline Local recurrence rates & 0.099 & 0.360 \\
\hline Bleeding & 0.096 & 0.392 \\
\hline Perforation rates & 0.818 & 0.303 \\
\hline Operation time & 0.344 & 0.711 \\
\hline
\end{tabular}

EGC and follow-up duration $<3.0$ years. Interaction test results indicated that publication year, mean age and percentage of male could affect the treatment effects between ESD and EMR for perforation (table 2). Finally, there was no publication bias between ESD and EMR for perforation ( $\mathrm{p}$ value for Egger: 0.818; $\mathrm{p}$ value for Begg: 0.303 ; table 3 ).

\section{Operation time}

Data for the effectiveness of ESD versus EMR for operation time were available in eight studies. We found that ESD was correlated with longer operation time as compared with EMR (SMD: 1.12; 95\% CI: 0.13 to 2.10; $\mathrm{p}=0.026$; with substantial heterogeneity; figure 8 ). The results of sensitivity analyses indicated that the conclusion was variable by excluding several studies (online supplementary file 3). The findings from subgroup analyses indicated that ESD was associated with longer operation time if: the study was published before 2010 , the study had non-concurrent design, sample size was $\geq 100$, mean age was $\geq 70.0$ years, percentage of male was $\geq 70 \%$, there were patients with recurrent EGC and the follow-up duration was $\geq 3.0$ years. Nevertheless, ESD was associated with shorter operation time compared with EMR if the study was published after 2010 (table 2). Finally, no significant publication bias for operation time was observed ( $\mathrm{p}$ value for Egger: 0.344; $\mathrm{p}$ value for Begg: 0.711 ; table 3$)$. 
Odds ratio

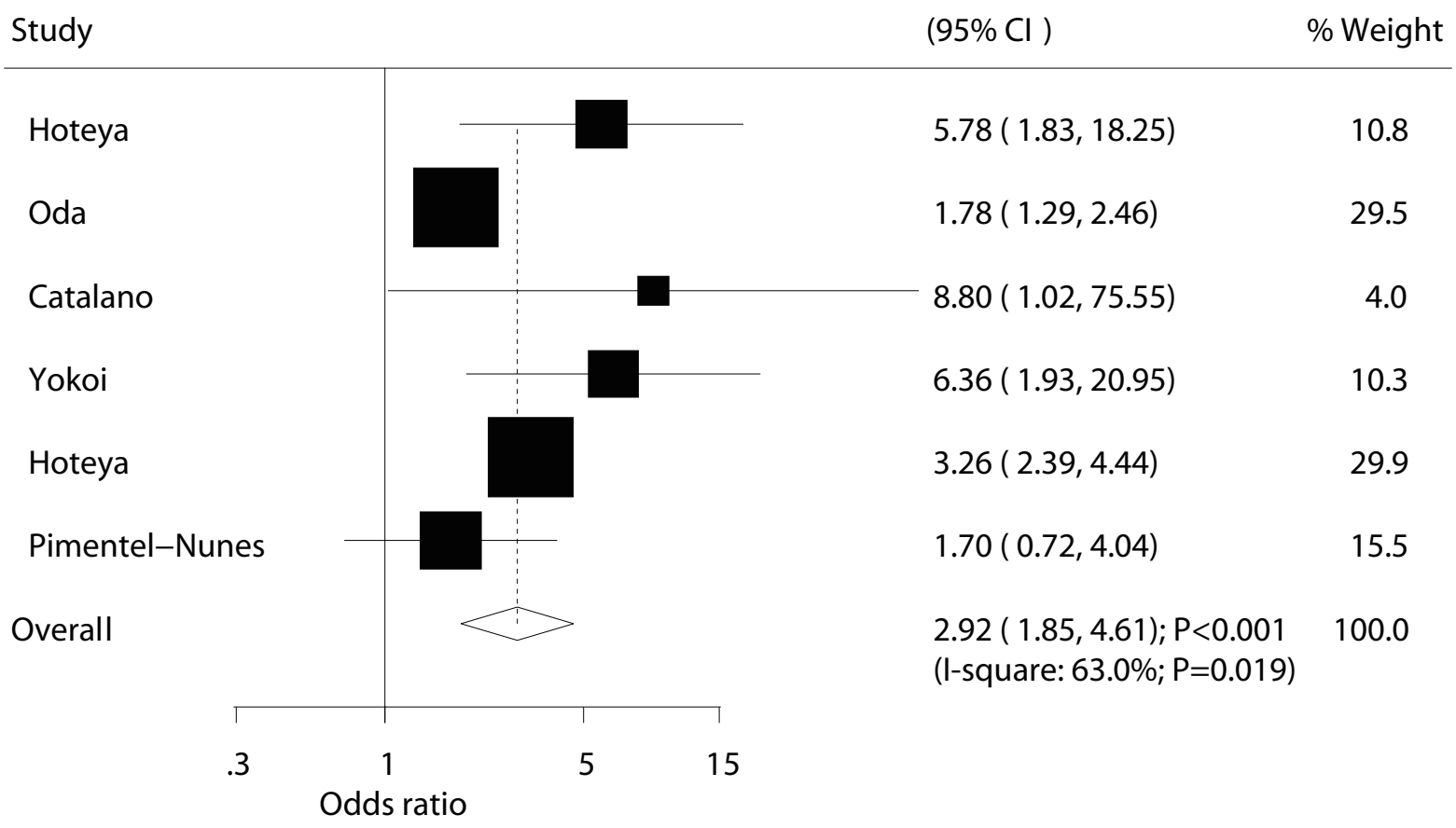

Figure 4 Effect of endoscopic submucosaldissection on the incidence of curative resection in patients with early gastric cancer.

\section{DISCUSSION}

Since the effectiveness of ESD versus EMR for patients with EGC has been previously investigated by different researchers, it can be very useful to summarise the results from these same studies via meta-analysis, which in turn could effectively assess the treatment effects. ${ }^{44}$ This systematic review and meta-analysis included 18 observational studies and 6723 patients with EGC. Briefly, we found that patients with EGC who underwent ESD had higher incidence of en bloc resection, complete resection, curative resection and lower risk of local recurrence compared with patients who received EMR. Yet, ESD

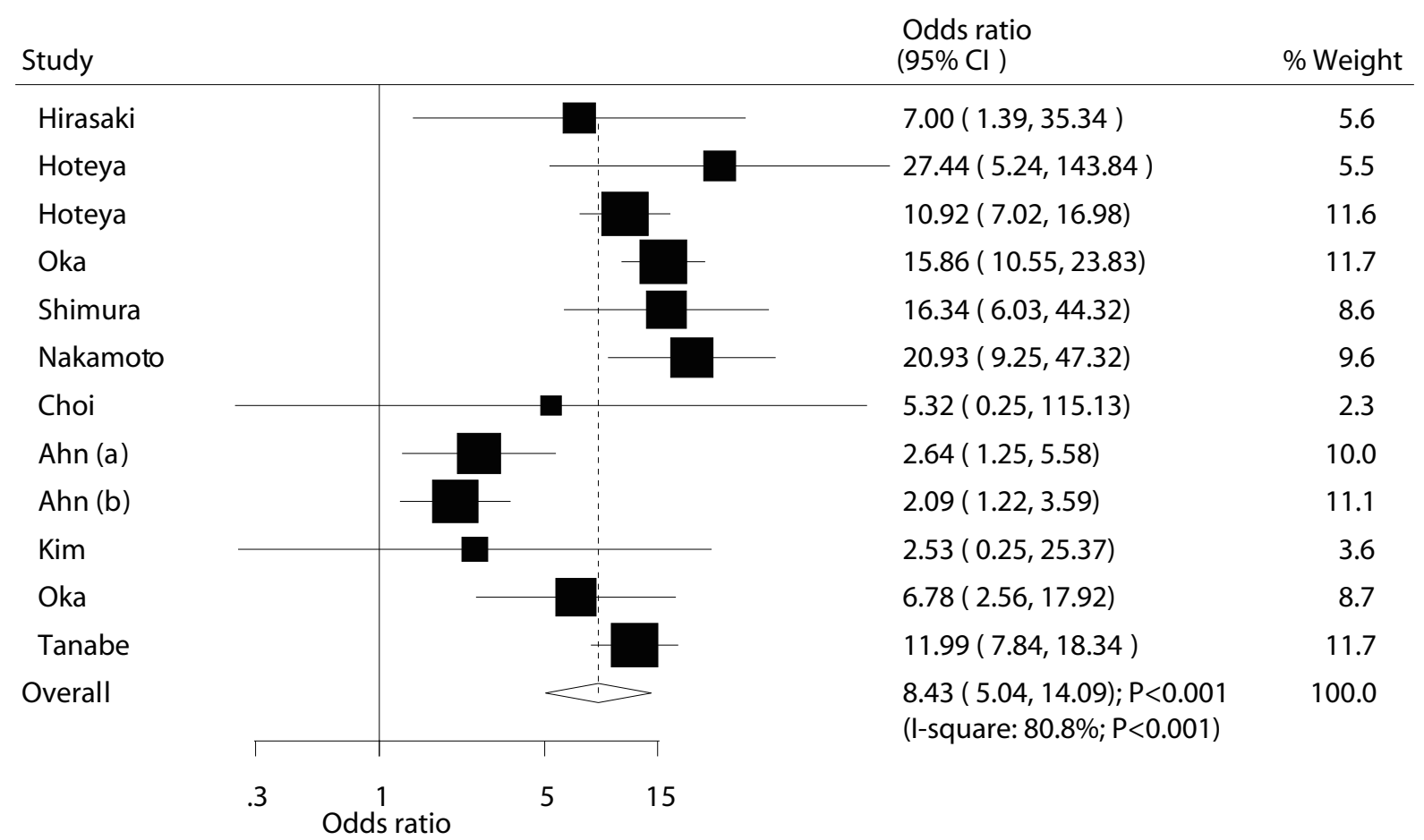

Figure 3 Effect of endoscopic submucosaldissection on the incidence of complete resection in patients with early gastric cancer. 


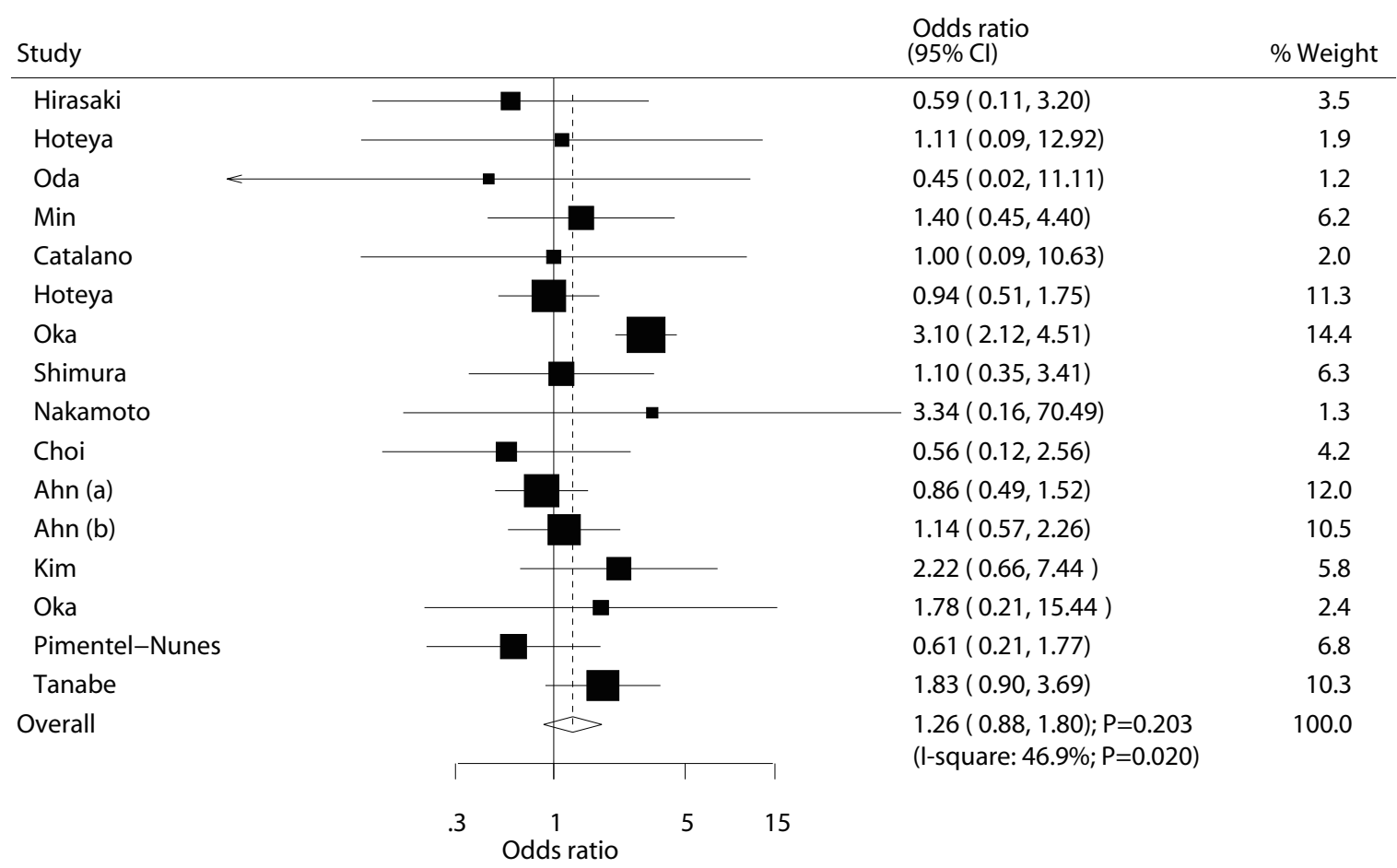

Figure 6 Effect of endoscopic submucosaldissection on the risk of bleeding in patients with early gastric cancer.

was associated with an increased risk of perforation and longer operation time. Furthermore, no significant difference in post-treatment bleeding was found between the two approaches. Although results from subgroup analyses were mostly consistent with overall analysis, the treatment effect of ESD versus EMR in patients with EGC might be biased by certain features observed in different studies.
A previous meta-analysis evaluated the efficacy and safety of ESD compared with EMR for patients with EGC, concluding that the benefit of ESD could overweight the risk of perforation. Furthermore, the risk of bleeding events between ESD and EMR was statistically significant. ${ }^{45}$ Moreover, Lian et al conducted a meta-analysis of eight retrospective studies and found ESD versus EMR

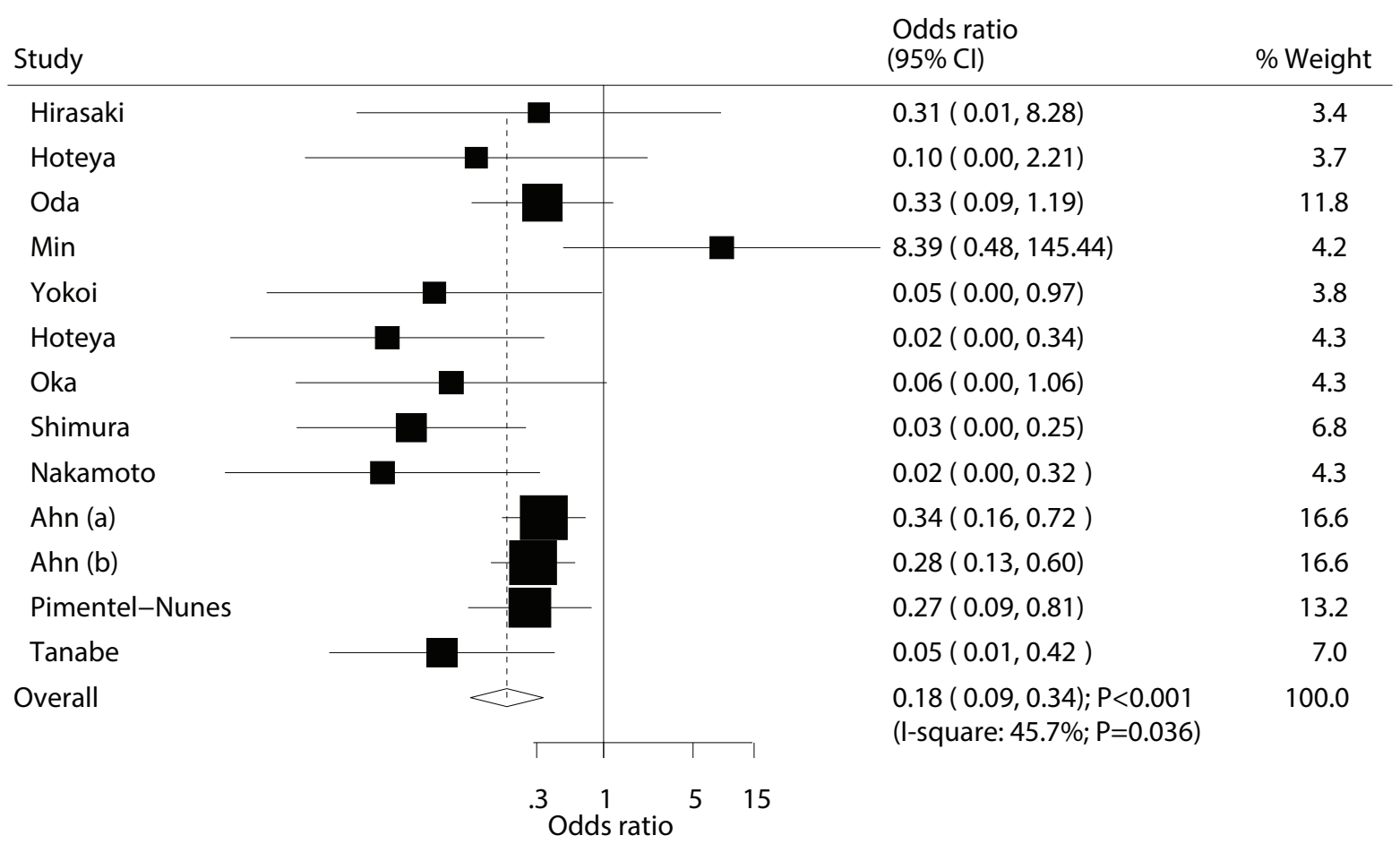

Figure 5 Effect of endoscopic submucosaldissection on the risk of local recurrence in patients with early gastric cancer. 
Standardised mean differene

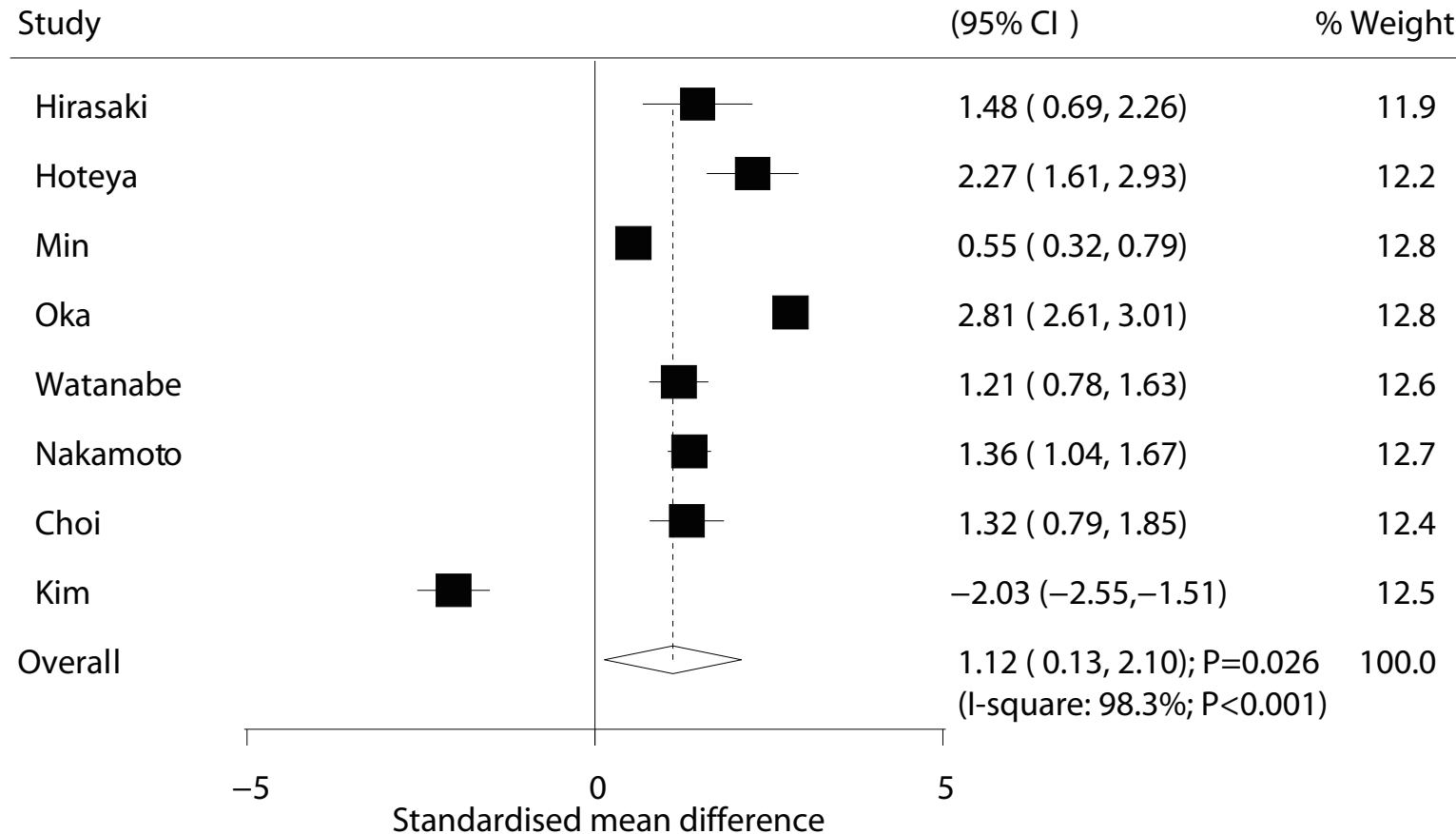

Figure 8 Effect of endoscopic submucosaldissection on operation time in patients with early gastric cancer.

shows improved incidence of en bloc resection, histologically complete resection and local recurrence, whereas an increased risk of perforation was detected. ${ }^{46}$ The study conducted by Facciorusso et al based on 10 retrospective studies and found ESD shows superior effectiveness but higher complication risk as compared with EMR for EGC. ${ }^{47}$ The recently updated study enrolled 18 retrospective studies and found the increased incidences of complete resection, en bloc resection, and reduced local recurrence but associated with longer operative time and increased risk of gastric perfusion. ${ }^{48}$ Nevertheless, previous meta-analyses failed to report the summary analysis based on disease status, as well as whether the effectiveness of ESD versus EMR differed in view to other factors. Moreover, several new studies can be involved in this meta-analysis for re-evaluation. Therefore, we

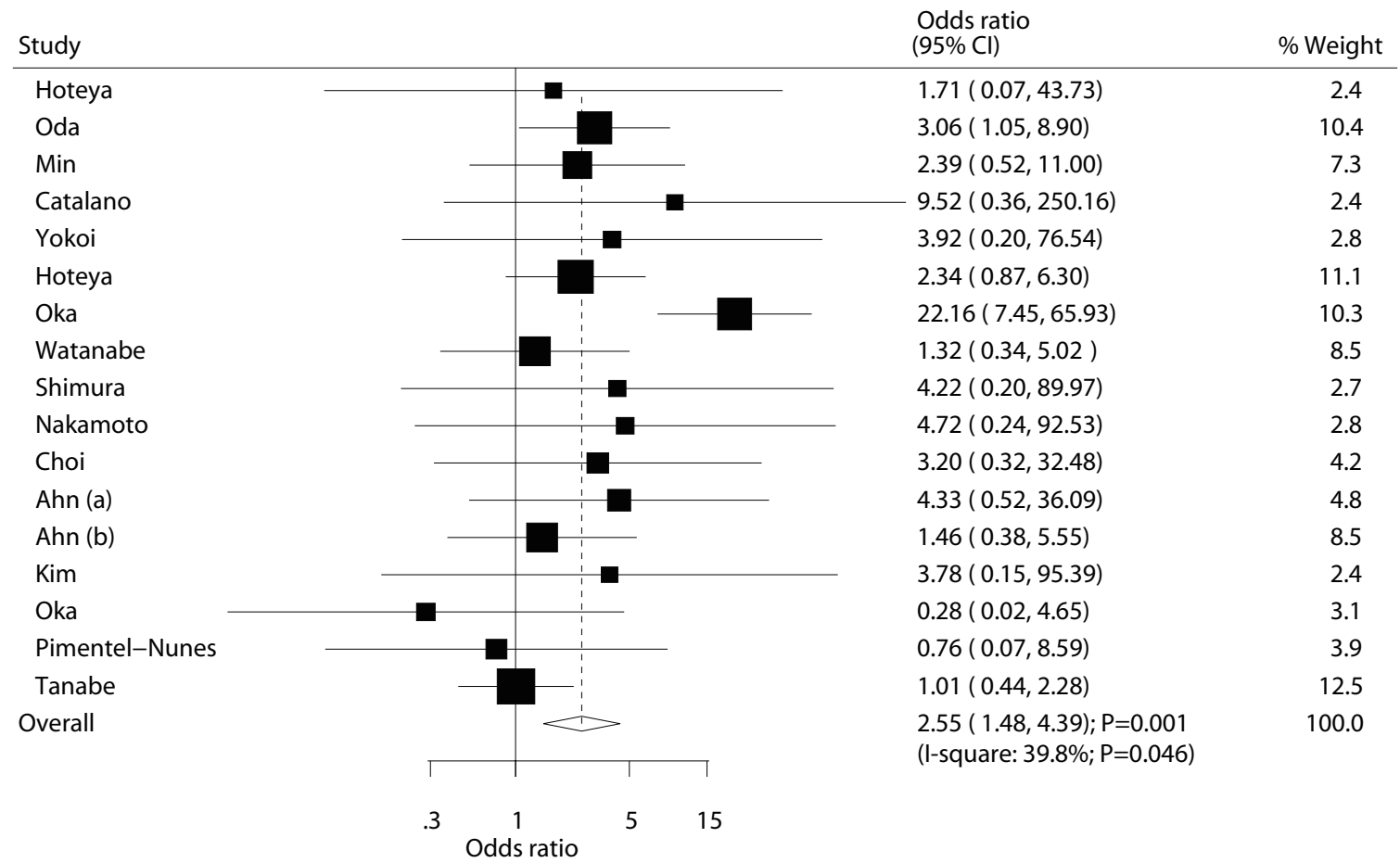

Figure 7 Effect of endoscopic submucosaldissection on the risk of perforation in patients with early gastric cancer. 
conducted this comprehensive quantitative meta-analysis to determine the treatment effects of ESD versus EMR in patients with EGC.

Our results indicated that ESD was associated with the increased incidence of en bloc resection, complete resection, curative resection and local recurrence compared with EMR; similar conclusions have been obtained in almost all included studies. Five studies reported no significant difference between ESD and EMR for the risk of local recurrence. We presume that this occurred due to small number of events observed and acquired broad 95\% CIs, which was not statistically significant. Additionally, several factors contributed to the treatment effectiveness of ESD versus EMR. First, en bloc resection rate was significantly higher in more than $70 \%$ male patients. This could be explained with different disease status. Second, publication year, mean age, percentage of male and follow-up duration could have biased the incidence of complete resection; the reason for this could be that the incidence of complete resection was correlated with statistical power, size of tumour and lifestyle of included patients. Third, the incidence of curative resection could be affected by sample size, disease status and follow-up duration. The reason for this could be the imbalance of number of studies in corresponding subsets. Finally, ESD was associated with lower risk of local recurrence in all subsets, while study design might affect effect size of summary results. This could be due to only one study with non-concurrent cohort design that reported the incidence of local recurrence; nonetheless, this result might vary and thus the effectiveness of ESD versus EMR for the needs of patients with EGC to be further verified.

There was no significant difference between ESD and EMR for the risk of bleeding, while ESD was associated with an increased risk of perforation as compared with EMR. Furthermore, no significant differences for bleeding events were persisted in all of subsets, which could be explained with the mild risk and fewer events than expected. In addition, publication year, mean age and percentage of male could affect the risk of perforation. These factors were correlated with statistical power, tumour size and lifestyle, which could affect the risk of perforation. Moreover, since the perforation was not caused life-threatening complication directly, and could lower with accumulated experience of operators. Therefore, the benefit of ESD could overweight harms in patients with EGC. Finally, ESD was associated with longer operation time compared with EMR. The reason could be that ESD technique included combined procedure of cutting and coagulation by electrosurgical simultaneously. Thus, EMR was easier for patients to access than ESD.

The limitations of the present meta-analysis should be highlighted. First, moderate or substantial heterogeneity among included studies was observed, which all not fully interpretation. Second, all of the included studies with observational design and uncontrolled confounders might biases the summary results. Third, the subgroup analyses according to macroscopic type and lymph node metastases were not carried out due to few studies reported these data, which might affect the prognosis of EGC. Fourth, this quantitative analysis was based on published studies and thus publication bias was inevitable. Finally, the summary analysis was based on pooled data and individual data were not available, which restricted us from conducting more detailing analysis.

The findings of this meta-analysis indicated that patients with EGC receiving ESD had higher incidence of en bloc resection, complete resection, and curative resection. Further, ESD could protect against the risk of local recurrence compared with EMR. In addition, ESD could lead to an increased risk of perforation due to complicated technique. Moreover, the risk of bleeding between ESD and EMR was not statistically significant. Further largescale prospective studies should be conducted to verify the detailed analysis in this quantitative analysis.

Contributors MT: conception and design of the study, critical revision, acquisition of data, analysis and interpretation of data, drafting the article, final approval; $\mathrm{XZ}$ : acquisition of data, analysis and interpretation of data, drafting the article, final approval; MH: interpretation of data, revising the article, final approval; JP interpretation of data, revising the article, final approval.

Funding This research received no specific grant from any funding agency in the public, commercial or not-for-profit sectors.

Competing interests None declared.

Patient consent for publication Not required.

Provenance and peer review Not commissioned; externally peer reviewed.

Data availability statement No data are available.

Open access This is an open access article distributed in accordance with the Creative Commons Attribution Non Commercial (CC BY-NC 4.0) license, which permits others to distribute, remix, adapt, build upon this work non-commercially, and license their derivative works on different terms, provided the original work is properly cited, appropriate credit is given, any changes made indicated, and the use is non-commercial. See: http://creativecommons.org/licenses/by-nc/4.0/.

\section{REFERENCES}

1 Jemal A, Bray F, Center MM, et al. Global cancer statistics. CA Cancer J Clin 2011;61:69-90.

2 Jemal A, Siegel R, Xu J, et al. Cancer statistics, 2010. CA Cancer J Clin 2010;60:277-300.

3 Crew KD, Neugut Al. Epidemiology of gastric cancer. World J Gastroenterol 2006;12:354-62.

4 Shimizu S, Tada M, Kawai K. Early gastric cancer: its surveillance and natural course. Endoscopy 1995;27:27-31.

5 Ikeda Y, Mori M, Koyanagi N, et al. Features of early gastric cancer detected by modern diagnostic technique. J Clin Gastroenterol 1998;27:60-2.

6 Ishikawa S, Togashi A, Inoue M, et al. Indications for EMR/ESD in cases of early gastric cancer: relationship between histological type, depth of wall invasion, and lymph node metastasis. Gastric Cancer 2007;10:35-8.

7 Tada M, Shimada M, Murakami F, et al. Development of the STRIPOFF biopsy. Gastroenterol Endosc 1984;26:833-9.

8 Tada M, Murakami A, Karita M, et al. Endoscopic resection of early gastric cancer. Endoscopy 1993;25:445-50.

9 Gotoda T, Yanagisawa A, Sasako M, et al. Incidence of lymph node metastasis from early gastric cancer: estimation with a large number of cases at two large centers. Gastric Cancer 2000;3:219-25.

10 Korenaga D, Haraguchi M, Tsujitani S, et al. Clinicopathological features of mucosal carcinoma of the stomach with lymph node metastasis in eleven patients. Br J Surg 1986;73:431-3.

11 Tanabe S, Koizumi W, Mitomi H, et al. Clinical outcome of endoscopic aspiration mucosectomy for early stage gastric cancer. Gastrointest Endosc 2002;56:708-13. 
12 Eguchi T, Gotoda T, Oda I, et al. Is endoscopic one-piece mucosal resection essential for early gastric cancer? Digestive Endoscopy 2003;15:113-6.

13 Oda I, Gotoda T, Hamanaka H, et al. Endoscopic submucosal dissection for early gastric cancer: technical feasibility, operation time and complications from a large consecutive series. Digestive Endoscopy 2005;17:54-8.

14 Yamamoto H, Kawata H, Sunada K, et al. Successful en-bloc resection of large superficial tumors in the stomach and colon using sodium hyaluronate and small-caliber-tip transparent hood. Endoscopy 2003;35:690-4.

15 Oyama T, Kikuchi Y. Aggressive endoscopic mucosal resection in the upper Gl tract - Hook knife EMR method. Minim Invasive Ther Allied Technol 2002;11:291-5.

16 Oda I, Saito D, Tada M, et al. A multicenter retrospective study of endoscopic resection for early gastric cancer. Gastric Cancer 2006;9:262-70.

17 Oka S, Tanaka S, Kaneko I, et al. Advantage of endoscopic submucosal dissection compared with EMR for early gastric cancer. Gastrointest Endosc 2006;64:877-83.

18 Stroup DF, Berlin JA, Morton SC, et al. Meta-analysis of observational studies in epidemiology: a proposal for reporting. meta-analysis of observational studies in epidemiology (MOOSE) group. JAMA 2000;283:2008-12.

19 Wells G, Shea B, O'Connell D. The Newcastle-Ottawa Scale (NOS) for assessing the quality of nonrandomised studies in meta-analyses. Ottawa (ON): Ottawa Hospital Research Institute, 2009. Available: http://www.ohri.ca/programs/ clinical_epidemiology /oxford.htm

20 DerSimonian R, Laird N. Meta-analysis in clinical trials. Control Clin Trials 1986;7:177-88.

21 Ades AE, Lu G, Higgins JPT. The interpretation of randomeffects meta-analysis in decision models. Med Decis Making 2005;25:646-54.

22 Deeks J, Higgins J, Altman D. Analyzing data and undertaking meta-analyses. In: Higgins J, Green S, eds. Cochrane Handbook for systematic reviews of interventions 5.0.1. Oxford, UK: The Cochrane Collaboration, 2008.

23 Higgins JPT, Thompson SG, Deeks JJ, et al. Measuring inconsistency in meta-analyses. BMJ 2003;327:557-60.

24 Tobias A. Assessing the influence of a single study in meta-analysis. Stata Tech Bull 1999;47:15-17.

25 Altman DG, Bland JM. Statistics notes: interaction revisited: the difference between two estimates. BMJ 2003;326:219.

26 Egger M, Smith GD, Schneider M, et al. Bias in meta-analysis detected by a simple, graphical test. BMJ 1997;315:629-34.

27 Begg CB, Mazumdar M. Operating characteristics of a RANK correlation test for publication bias. Biometrics 1994;50:1088-101.

28 Hirasaki S, Kanzaki H, Matsubara M, et al. Treatment of gastric remnant cancer post distal gastrectomy by endoscopic submucosal dissection using an insulation-tipped diathermic knife. World $J$ Gastroenterol 2008;14:2550-5.

29 Hoteya S, lizuka T, Kikuchi D, et al. Clinical advantages of endoscopic submucosal dissection for gastric cancers in remnant stomach surpass conventional endoscopic mucosal resection. Digestive Endoscopy 2010;22:17-20.

30 Min B-H, Lee JH, Kim JJ, et al. Clinical outcomes of endoscopic submucosal dissection (ESD) for treating early gastric cancer: comparison with endoscopic mucosal resection after circumferential precutting (EMR-P). Dig Liver Dis 2009;41:201-9.

31 Catalano F, Trecca A, Rodella L, et al. The modern treatment of early gastric cancer: our experience in an Italian cohort. Surg Endosc 2009;23:1581-6.

32 Yokoi C, Gotoda T, Hamanaka H, et al. Endoscopic submucosal dissection allows curative resection of locally recurrent early gastric cancer after prior endoscopic mucosal resection. Gastrointest Endosc 2006;64:212-8.

33 Hoteya S, lizuka T, Kikuchi D, et al. Benefits of endoscopic submucosal dissection according to size and location of gastric neoplasm, compared with conventional mucosal resection. J Gastroenterol Hepatol 2009;24:1102-6.

34 Watanabe K, Ogata S, Kawazoe S, et al. Clinical outcomes of EMR for gastric tumors: historical pilot evaluation between endoscopic submucosal dissection and conventional mucosal resection. Gastrointest Endosc 2006;63:776-82.

35 Shimura T, Sasaki M, Kataoka H, et al. Advantages of endoscopic submucosal dissection over conventional endoscopic mucosa resection. J Gastroenterol Hepatol 2007;22:821-6.

36 Nakamoto S, Sakai Y, Kasanuki J, et al. Indications for the use of endoscopic mucosal resection for early gastric cancer in Japan: a comparative study with endoscopic submucosal dissection. Endoscopy 2009;41:746-50.

37 Choi KS, Jung HY, Choi KD, et al. Endoscopic submucosal dissection for gastric tumors: complete resection rate, resection time and complications in comparison with endoscopic mucosal resection after circumferential mucosal incision with a needle knife. Korean J Gastrointest Endosc 2006;32:326-32.

38 Ahn JY, Jung H-Y, Choi KD, et al. Endoscopic and oncologic outcomes after endoscopic resection for early gastric cancer: 1370 cases of absolute and extended indications. Gastrointest Endosc 2011;74:485-93.

$39 \mathrm{Kim} \mathrm{HH}$, Kim GH, Kim JH, et al. The efficacy of endoscopic submucosal dissection of type I gastric carcinoid tumors compared with conventional endoscopic mucosal resection. Gastroenterol Res Pract 2014;2014:1-7.

40 Oka S, Tanaka S, Higashiyama M, et al. Clinical validity of the expanded criteria for endoscopic resection of undifferentiated-type early gastric cancer based on long-term outcomes. Surg Endosc 2014;28:639-47.

41 Pimentel-Nunes P, Mourão F, Veloso N, et al. Long-term follow-up after endoscopic resection of gastric superficial neoplastic lesions in Portugal. Endoscopy 2014;46:933-40.

42 Tanabe S, Ishido K, Higuchi K, et al. Long-Term outcomes of endoscopic submucosal dissection for early gastric cancer: a retrospective comparison with conventional endoscopic resection in a single center. Gastric Cancer 2014;17:130-6.

43 Watanabe T, Kume K, Taip M, et al. Gastric mucosal cancer smaller than $7 \mathrm{~mm}$ can be treated with conventional endoscopic mucosal resection as effectively as with endoscopic submucosal dissection. Hepato-gastroenterology 2010;57:668-73.

44 Feichtinger J, Aldeailej I, Anderson R, et al. Meta-Analysis of clinical data using human meiotic genes identifies a novel cohort of highly restricted cancer-specific marker genes. Oncotarget 2012;3:843-53.

45 Park Y-M, Cho E, Kang H-Y, et al. The effectiveness and safety of endoscopic submucosal dissection compared with endoscopic mucosal resection for early gastric cancer: a systematic review and meta-analysis. Surg Endosc 2011;25:2666-77.

46 Lian J, Chen S, Zhang Y, et al. A meta-analysis of endoscopic submucosal dissection and EMR for early gastric cancer. Gastrointest Endosc 2012;76:763-70.

47 Facciorusso Aet al. Endoscopic submucosal dissection vs endoscopic mucosal resection for early gastric cancer: A metaanalysis. World J Gastrointest Endosc 2014;6:555-63.

48 Zhao $\mathrm{Y}$, Wang $\mathrm{C}$. Long-term clinical efficacy and perioperative safety of endoscopic submucosal dissection versus endoscopic mucosal resection for early gastric cancer: an updated meta-analysis. Biomed Res Int 2018;2018. 